\title{
HUBUNGAN PENGETAHUAN LANSIA TENTANG SENAM LANSIA DENGAN PRAKTIK SENAM LANSIA DI POSYANDU LANSIA
}

\author{
Aprilia Nurtika Sari \\ (Akademi Kebidanan Dharma Husada Kediri)
}

\begin{abstract}
Among the vulnerable population are the elderly. One of the physical activities recommended for the elderly is elderly exercise. This study aims to identify the correlation between the knowledge of the elderly about elderly exercise with the practice of elderly exercise in the Elderly Posyandu in Kepuh Village, Kertosono District, Nganjuk Regency. The research design used was analytic with a cross sectional approach. The population in this study were all elderly registered in the Elderly Posyandu in Kepuh Village, Kertosono District, Nganjuk Regency, totaling 30 people. The sample consisted of 30 people who were determined by total sampling technique. To analyze the correlation, the Spearman Rho test was used. The results obtained from 30 respondents, there were 13 respondents (43.33\%) who had sufficient knowledge and did not routinely do elderly exercise, 12 respondents (40\%) had good knowledge and routinely did elderly exercise. There is a correlation between knowledge about elderly exercise and the practice of elderly exercise. The better the knowledge of the elderly about elderly exercise, the more routine they will participate in elderly exercise. These results indicate that knowledge has an important role to play in increasing motivation and shaping one's health behavior. Therefore, health workers are expected to be active in providing health information through counseling at the elderly posyandu and other community activities.
\end{abstract}

Keywords: Correlation; Knowledge; Practice; Elderly exercice

\begin{abstract}
Abstrak
Penduduk rentan diantaranya adalah lanjut usia. Salah satu aktifitas fisik yang direkomendasikan untuk lansia adalah senam lansia. Penelitian ini bertujuan untuk mengidentifikasi hubungan pengetahuan lansia tentang senam lansia dengan praktik senam lansia di Posyandu Lansia Desa Kepuh, Kecamatan Kertosono, Kabupaten Nganjuk. Desain penelitian yang digunakan adalah analitik dengan pendekatan cross sectional. Populasi dalam penelitian ini adalah semua lansia yang terdaftar di Posyandu Lansia Desa Kepuh Kecamatan Kertosono Kabupaten Nganjuk berjumlah 30 orang. Sampel berjumlah 30 orang yang ditentukan dengan teknik total sampling. Untuk menganalisis hubungan digunakan uji Spearman Rho. Hasil penelitian didapatkan dari 30 responden, terdapat 13 responden $(43,33 \%)$ yang memiliki pengetahuan cukup dan tidak rutin melakukan senam lansia, 12 responden (40\%) memiliki pengetahuan baik dan rutin melakukan senam lansia. Ada hubungan antara pengetahuan tentang senam lansia dengan praktik senam lansia. Semakin baik pengetahuan lansia tentang senam lansia, maka semakin rutin pula ia mengikuti senam lansia. Hasil tersebut menunjukkan bahwa pengetahuan mempunyai peran penting untuk meningkatkan motivasi dan membentuk perilaku kesehatan seseorang. Oleh karena itu, petugas kesehatan diharapkan aktif memberikan informasi-informasi kesehatan melalui penyuluhan di posyandu lansia maupun kegiatan masyarakat lainnya.
\end{abstract}

Kata Kunci: Hubungan; Pengetahuan; Praktik; Senam; Lansia 


\section{PENDAHULUAN}

Penduduk rentan diantaranya adalah lanjut usia, yaitu seseorang yang sudah mencapai usia 60 tahun. Penuaan penduduk pada abad 21 merupakan suatu fenomena penting yang tidak dapat dihindari baik oleh negara maju maupun negara berkembang. Berdasarkan data Perserikaan Bangsa-bangsa (PBB) tentang World Population Ageing, diperkirakan pada tahun 2015 terdapat 901 juta jiwa penduduk lanjut usia di dunia. Jumlah tersebut diproyeksikan terus meningkat mencapai 2 (dua) miliar jiwa pada tahun 2050. Seperti halnya yang terjadi di negara-negara di dunia, Indonesia juga mengalami penuaan penduduk. Tahun 2019, jumlah lansia Indonesia diproyeksikan akan meningkat menjadi 27,5 juta atau $10,3 \%$, dan 57,0 juta jiwa atau $17,9 \%$ pada tahun 2045 . $^{1}$

Lanjut usia sering dikaitkan dengan usia yang sudah tidak produktif, bahkan diasumsikan sebagai beban bagi usia produktif. Hal ini disebabkan karena dengan bertambahnya umur, fungsi fisiologis mengalami penurunan akibat proses degeneratif (penuaan) sehingga mengakibatkan lansia rentan terkena gangguan kesehatan. ${ }^{2}$ Aktivitas fisik sangat penting untuk mencegah banyak masalah kesehatan kronis dan untuk meningkatkan kesehatan mental serta kualitas hidup pada kelompok lanjut usia. Aktivitas fisik telah menjadi prioritas dalam kegiatan promosi kesehatan, terutama untuk kesehatan individu. Aktivitas fisik pada lansia menjadi kebijakan kesehatan di Inggris ${ }^{3}$.

Salah satu aktifitas fisik yang direkomendasikan untuk lansia adalah senam lansia. Senam lansia adalah olahraga ringan dan mudah dilakukan, tidak memberatkan yang diterapkan pada lansia. Aktifitas olahraga ini akan membantu tubuh agar tetap bugar dan tetap segar karena melatih tulang tetap kuat, mendorong jantung bekerja optimal dan membantu menghilangkan radikal bebas yang berkeliaran di dalam tubuh. ${ }^{4}$ Teori kognitif sosial menyebutkan bahwa pengetahuan tentang manfaat dari dilakukannya aktifitas fisik dapat meningkatkan motivasi untuk melakukan aktifitas fisik tersebut secara rutin. Sedangkan, kepercayaan umum orang bahwa aktifitas fisik bermanfaat untuk kesehatan tidak bisa digunakan untuk memperkirakan motivasi dan perilaku seseorang. ${ }^{5}$

Dalam penelitian Widyastuti (2012), disebutkan bahwa tingkat pengetahuan tentang senam lansia memiliki korelasi positif dengan keaktifan mengikuti senam lansia. ${ }^{6}$ Begitu juga dengan penelitian Kurniawati, dkk (2019), hasil penelitian menunjukkan bahwa tingkat pengetahuan lansia dalam kategori kurang sebanyak 37 orang $(46,3 \%)$ dan tidak mengikuti senam sebanyak 39 responden (48,8\%). Berdasakan hasil uji statistik didapatkan nilai $x 2$ sebesar 66,615 dan nilai $p$ value sebesar 0,000 yang artinya ada hubungan tingkat pengetahuan lansia tentang senam lansia dalam keikutsertaan dalam pelaksanaan senam lansia di Kelurahan Pudakpayung Kecamatan Banyumanik Kota Semarang. ${ }^{2}$ Dari hasil studi pendahuluan yang dilakukan peneliti di Posyandu Lansia terhadap 10 orang lansia, didapatkan 6 orang lansia $(60 \%)$ mengetahui manfaat senam lansia dan rutin mengikuti 
senam lansia, sedangkan 3 orang lansia (30\%) mengetahui manfaat senam lansia namun jarang mengikuti dan 1 orang lansia (10\%) tidak pernah mengikuti senam lansia.

Pemilihan waktu pelaksanaan menjadi salah satu faktor penting dalam upaya meningkatkan partisipasi lansia dalam kegiatan posyandu lansia. Kegiatan posyandu yang dilaksanakan pada hari Minggu pagi akan lebih mempermudah lansia untuk mengikutinya. Hal ini dikarenakan hari Minggu adalah hari libur, sehingga anggota keluarga yang tidak bisa mengantar pada hari-hari biasa maka pada hari Minggu mereka lebih leluasa untuk mengantar lansia mengikuti posyandu. Lansia yang menghadiri kegiatan posyandu lansia akan mendapat informasi yang benar tentang bagaimana cara hidup sehat dengan segala keterbatasan atau masalah kesehatan yang biasa dialami oleh lansia. Pengalaman serta pengetahuan lansia tersebut dapat meningkatkan minat dan motivasi mereka untuk selalu mengikuti kegiatan-kegiatan yang diadakan oleh posyandu lansia, khususnya kegiatan senam lansia yang sudah menjadi agenda rutin Posyandu Lansia. Penelitian ini bertujuan untuk mengidentifikasi hubungan pengetahuan lansia tentang senam lansia dengan praktik senam lansia di Posyandu Lansia Desa Kepuh, Kecamatan Kertosono, Kabupaten Nganjuk.

\section{METODE PENELITIAN}

Penelitian ini menggunakan desain penelitian analitik dengan pendekatan cross sectional. Populasi dalam penelitian ini adalah semua lansia yang terdaftar di Posyandu Lansia Desa Kepuh Kecamatan Kertosono Kabupaten Nganjuk berjumlah 30 orang. Sampel merupakan semua lansia yang terdaftar di Posyandu Lansia Desa Kepuh Kecamatan Kertosono Kabupaten Nganjuk berjumlah 30 orang. Teknik sampling menggunakan total sampling. Pengumpulan data menggunakan kuesioner yang berisi pertanyaan tentang karakteristik responden, pengetahuan dan keikutsertaan dalam praktik senam lansia. Variabel independennya adalah pengetahuan. Pengetahuan yang dimaksud dalam penelitian ini adalah segala sesuatu yang diketahui lansia tentang definisi, tujuan, prinsip, manfaat, dan prosedur senam lansia. Hasil akhir dari pengetahuan dikategorikan berdasarkan kriteria baik jika skor $76-100 \%$, cukup jika skor $56-75 \%$, dan kurang jika skor $<56 \%$. Variabel dependen dalam penelitian ini adalah praktik senam lansia, maksudnya keikutsertaan lansia dalam kegiatan senam lansia. Pengkategorian praktik senam lansia ini didasarkan pada kriteria rutin jika dilakukan 4-5x/bulan, tidak rutin jika dilakukan $<4 x$ /bulan.

Penelitian ini menggunakan analisis statistik univariat dan bivariat. Analisis univariat digunakan untuk mendeskripsikan karakteristik setiap subyek penelitian. Dalam penelitian ini disajikan dalam bentuk distribusi frekuensi dan persentase. Analisis bivariat dilakukan dengan uji Spearman's Rho untuk menguji hipotesis hubungan yang signifikan antara pengetahuan tentang senam lansia dengan praktik senam lansia. 


\section{HASIL PENELITIAN}

Tabel 1. Distribusi Frekuensi Responden Berdasarkan Karakteristik Umur, Pendidikan dan Pekerjaan di Posyandu Lansia Desa Kepuh Kecamatan Kertosono Kabupaten Nganjuk

\begin{tabular}{cccc}
\hline Variabel & Kategori & $f$ & Persentase (\%) \\
\hline Umur & $50-60$ tahun & 6 & 20 \\
& $>60$ tahun & 24 & 80 \\
\hline Pendidikan & SD & 20 & 66,67 \\
& SMP & 7 & 23,33 \\
& SMA & 2 & 6,67 \\
& PT/ Akademi & 1 & 3,33 \\
\hline Pekerjaan & Tidak bekerja & 23 & 76,67 \\
& Bekerja & 7 & 23,33 \\
\hline
\end{tabular}

Sumber: Data Primer 2019

Tabel 1 menunjukkan mayoritas responden berumur $>60$ tahun $(80 \%)$, berpendidikan SD $(66,67 \%)$, dan tidak bekerja $(76,67 \%)$.

Tabel 2. Distribusi Frekuensi Responden Berdasarkan Pengetahuan dan Praktik Senam Lansia di Posyandu Lansia Desa Kepuh Kecamatan Kertosono Kabupaten Nganjuk

\begin{tabular}{cccc}
\hline Variabel & Kategori & $f$ & Persentase (\%) \\
\hline Pengetahuan & Baik & 13 & 43,33 \\
& Cukup & 14 & 46,67 \\
& Kurang & 3 & 10 \\
\hline Praktik senam lansia & Rutin & 13 & 43,33 \\
& Tidak rutin & 17 & 56,67 \\
\hline
\end{tabular}

Sumber: Data Primer 2019

Tabel 2 menunjukkan mayoritas responden memiliki pengetahuan cukup (46,67\%) dan tidak rutin mengikuti senam lansia (56,67\%).

Tabel 3. Hubungan Pengetahuan tentang Senam Lansia dengan Praktik Senam Lansia di Posyandu Lansia Desa Kepuh Kecamatan Kertosono Kabupaten Nganjuk

\begin{tabular}{|c|c|c|c|c|c|c|}
\hline \multirow[t]{3}{*}{ Variabel } & \multicolumn{4}{|c|}{ Praktik Senam Lansia } & & \\
\hline & \multicolumn{2}{|c|}{ Rutin } & \multicolumn{2}{|c|}{ Tidak Rutin } & \multicolumn{2}{|c|}{ Jumlah } \\
\hline & $\mathrm{n}$ & $\%$ & $\mathrm{n}$ & $\%$ & $\mathrm{n}$ & $\%$ \\
\hline \multicolumn{7}{|l|}{ Pengetahuan } \\
\hline Baik & 12 & 40 & 1 & 3,33 & 13 & 43,33 \\
\hline Cukup & 1 & 3,33 & 13 & 43,33 & 14 & 46,67 \\
\hline Kurang & 0 & 0 & 3 & 10 & 3 & 10 \\
\hline Uji Spearman & $=0,675$ & & & $r_{s}$ tabe & & \\
\hline
\end{tabular}

Sumber: Data Primer, 2019

Tabel 3 menunjukkan mayoritas responden yang memiliki pengetahuan cukup, tidak rutin melakukan senam lansia (43,33\%). Dengan perhitungan uji statistik Spearman Rho didapatkan $r_{s}$ hitung sebesar 0,675 dengan tingkat siknifikasi $5 \%, r_{s}$ tabel sebesar 0,364 
sehingga $r_{s}$ hitung lebih besar dibandingkan dengan $r_{s}$ tabel $(0,675>0,364)$. Sehingga $H_{1}$ diterima, artinya ada hubungan pengetahuan tentang senam lansia dengan praktik senam lansia.

\section{PEMBAHASAN}

Berdasarkan hasil penelitian didapatkan bahwa mayoritas responden memiliki pengetahuan yang cukup tentang senam lansia (46,67\%). Namun, ada 3 responden (10\%) dengan pengetahuan tentang senam lansia yang masih kurang. Hasil penelitian ini sejalan dengan penelitian Rahmi, dkk (2016). Hasil penelitian tersebut menunjukkan bahwa dari 29 lansia di Panti Sosial Tresna Werdha Budi Pertiwi, 14 lansia (48,3\%) berpengetahuan baik, 14 lansia $(48,3 \%)$ berpengetahuan cukup dan hanya 1 lansia $(3,4 \%)$ berpengetahuan kurang. ${ }^{7}$ Pengetahuan adalah hasil dari tahu dan pengetahuan terjadi setelah seseorang melakukan suatu pengindraan terhadap kejadian tertentu. Sebagian pengetahuan manusia dapat diperoleh melalui mata dan telinga. ${ }^{8}$

Dalam proses penuaan, terjadi kehilangan massa otot secara progresif, terutama pada individu dengan aktivitas fisik yang rendah. Hilangnya massa otot dapat menyebabkan penurunan kekuatan dan kemampuan fisik secara progresif. Berkurangnya kekuatan otot dapat menghambat kinerja aktivitas umum kehidupan sehari-hari dan hilangnya massa otot dapat menyebabkan ketergantungan pada orang lain untuk melakukan satu atau lebih aktivitas sehari-hari. ${ }^{9}$. Pada lansia terjadi proses penuaan secara alamiah. Selama proses penuaan tersebut, terjadi proses menghilangnya kemampuan-kemampuan fisik, psikologis, sosial dan ekonomi. Menghilangnya kemampuan fisik tentunya juga akan mempengaruhi kemampuan lansia dalam mengolah informasi. Pengetahuan yang sifatnya dapat dirasakan atau aplikatif lebih mudah diterima oleh lansia dibandingkan pengetahun yang sifatnya teori. Hal inilah yang menyebabkan lansia mayoritas mampu menjawab benar pertanyaan tentang manfaat senam lansia. Mereka lebih mudah menjawab karena merasakan sendiri manfaat dari senam lansia.

Dari hasil penelitian didapatkan mayoritas responden tidak rutin mengikuti senam lansia $(56,67 \%)$. Berdasarkan umur, mayoritas responden berusia lebih dari 60 tahun (80\%). Umur merupakan salah satu penentu keaktifan lansia dalam beraktifitas. Semakin tua umur lansia, maka semakin terbatas juga aktifitas yang dilakukan ${ }^{10}$. Dengan bertambahnya umur, motivasi untuk berolahraga juga cenderung menurun. Rendahnya motivasi tersebut tidaklah mengejutkan mengingat individu yang lebih tua mungkin tidak berolahraga untuk tujuan penampilan dan pengakuan sosial. ${ }^{11}$ Manfaat dari aktivitas fisik terhadap kesehatan secara umum telah dikenal oleh lansia. Namun, penelitian melaporkan rendahnya aktivitas fisik dalam kelompok ini. Umumnya, lansia menganggap diri mereka sehat sehingga tidak perlu berolahraga dan banyak yang percaya bahwa mereka telah melakukan aktivitas fisik yang 
cukup untuk tetap sehat. Paradoksnya, lansia sering menggunakan kesehatan mereka yang buruk sebagai alasan untuk tidak berpartisipasi dalam aktivitas fisik. ${ }^{12}$

Dengan semakin bertambahnya umur, semakin terbatas juga kegiatan yang bisa dilakukan. Selain itu, sebagian besar responden mempunyai keluhan sehubungan dengan kondisi kesehatannya. Hal inilah yang semakin membuat mereka tidak rutin mengikuti senam lansia. Kondisi kesehatan yang menurun menyebabkan minat untuk melakukan aktifitas fisik juga ikut turun. Penyakit akut atau pengalaman seperti rawat inap bisa menjadi titik balik bagi lansia dan dapat memicu terjadinya perubahan perilaku kesehatan, misalnya membuat lansia rutin melakukan senam lansia. Hasil penelitian menunjukkan bahwa ada hubungan pengetahuan tentang senam lansia dengan praktik senam lansia. Sebanyak 12 responden yang memiliki pengetahuan baik rutin melakukan senam lansia (40\%).

Menurut Notoatmodjo dalam Suseno (2012), apabila penerimaan perilaku baru atau adopsi perilaku melalui proses yang didasari oleh pengetahuan dan sikap maka perilaku tersebut akan bersifat langgeng (long lasting), sebaliknya apabila perilaku itu tidak didasari dari pengetahuan dan kesadaran maka tidak akan berlangsung lama. ${ }^{13}$ Hasil penelitian ini sejalan dengan penelitian Widyastuti (2012), yang meneliti tentang hubungan tingkat pengetahuan tentang senam lansia dengan keaktifan mengikuti senam lansia di Unit Rehabilitasi Sosial Wening Wardoyo Ungaran. Hasil penelitian tersebut menyatakan bahwa ada hubungan antara tingkat pengetahuan tentang senam lansia dengan keaktifan mengikuti senam lansia. Kegiatan senam lansia bahkan sudah menjadi kegiatan rutin setiap pagi di tempat tersebut. ${ }^{6}$

Pengetahuan merupakan salah satu faktor yang dominan dalam membentuk perilaku seseorang. Seorang lansia yang sudah memiliki pengetahuan tentang senam lansia, maka selanjutnya dia akan menimbang-nimbang apakah akan mengikuti senam lansia atau tidak. Disinilah informasi yang benar dan menarik tentang senam lansia diperlukan. Salah satu cara untuk membuat informasi yang kita berikan menjadi menarik adalah dengan menonjolkan manfaat. Dengan mengetahui manfaat senam lansia, seorang lansia tidak akan berpikir panjang untuk segera melakukannya. Apalagi jika sudah merasakan sendiri manfaat senam lansia untuk kesehatan, tentu aktifitas tersebut akan menjadi kebiasaan yang bersifat langgeng.

Penduduk lansia di Indonesia di masa depan membawa dampak positif maupun negatif. Berdampak positif, apabila penduduk lansia berada dalam keadaan sehat, aktif dan produktif. Disisi lain, besarnya jumlah penduduk lansia menjadi beban jika lansia memiliki masalah penurunan kesehatan yang berakibat pada peningkatan biaya pelayanan kesehatan, penurunan pendapatan/penghasilan, peningkatan disabilitas, tidak adanya dukungan sosial dan lingkungan yang tidak ramah terhadap penduduk lansia. ${ }^{14}$ Salah satu upaya yang dilaksanakan untuk meningkatkan kesejahteraan lansia adalah pos pelayanan 
terpadu (posyandu) lansia yang merupakan pelayanan kesehatan bagi lansia. Pelayanan kesehatan di posyandu lansia meliputi pemeriksaan kesehatan fisik dan mental emosional, pemeriksaan status mental. Kegiatan lain yang biasa dilakukan sesuai kebutuhan dan kondisi setempat adalah penyuluhan, Pemberian Makanan Tambahan (PMT) dengan memperhatikan aspek kesehatan dan gizi lanjut usia dan kegiatan olah raga seperti senam lanjut usia, gerak jalan santai untuk meningkatkan kebugaran. ${ }^{15}$

Senam lansia mempunyai banyak manfaat. Diantaranya yaitu membantu mengurangi stress dan memperbaiki suasana hati. Perempuan menopause yang rutin berolahraga, mepunyai kualitas hidup yang lebih baik. Selain itu, mereka juga tidak memiliki keluhan yang berat terhadap gejala menopause yang dialami, baik dalam domain vasomotor, psikososial, fisik, maupun seksual. ${ }^{16,17}$ Meskipun mengalami keterbatasan fisik, banyak lansia yang rutin mengikuti senam lansia. Hal ini dikarenakan mereka sudah merasakan sendiri bahwa setelah rutin melakukan senam lansia, badan mereka terasa sehat dan bugar. Selain itu, dengan rutin mengikuti senam lansia, mereka juga akan sering bertemu dengan rekan sebaya. Dimana mereka dapat saling bercerita dan berbagi pengalaman tentang kondisi kesehatannya. Hal itu akan membuat mereka merasa bahagia. Dengan banyaknya lansia yang aktif mengikuti senam lansia, diharapkan lansia mendapat manfaat dari kegiatan tersebut sehingga lansia tetap bugar dan memiliki kualitas hidup yang lebih baik.

\section{SIMPULAN DAN SARAN}

Ada hubungan antara pengetahuan tentang senam lansia dengan praktik senam lansia. Semakin baik pengetahuan lansia tentang senam lansia, maka semakin rutin pula ia mengikuti senam lansia. Hasil tersebut menunjukkan bahwa pengetahuan mempunyai peran penting untuk meningkatkan motivasi dan membentuk perilaku kesehatan seseorang. Oleh karena itu, petugas kesehatan diharapkan aktif memberikan informasi-informasi kesehatan melalui penyuluhan di posyandu lansia maupun kegiatan masyarakat lainnya.

\section{DAFTAR PUSTAKA}

1. Heri L, Cicih MIS. Info Demografi BKKBN. Demogr BKKBN [Internet]. 2019;1:16. Available from: https://www.bkkbn.go.id/pocontent/uploads/info_demo_vol_1_2019_jadi.pdf

2. Agustina D, Rival A, Kurniawati N. Faktor -Faktor Yang Memotivasi Lansia Dalam Mengikuti Kegiatan Senam. Jurna Ilmu dan Teknol Kesehat. 2016;3:177-90.

3. Li Y, Du X, Zhang C, Wang S. Physical activity among the elderly in China: A qualitative study. Br J Community Nurs. 2013;18(7):340-50.

4. Sari AN, Istighosah N. Modul Senam Lansia. 2019. i-30.

5. Fredriksson SV, Alley SJ, Rebar AL, Hayman M, Vandelanotte C, Schoeppe S. How 
are different levels of knowledge about physical activity associated with physical activity behaviour in Australian adults? PLoS One. 2018;13(11):1-10.

6. Widyastuti VW, Indriati PA, Supriyadi. Hubungan Tingkat Pengetahuan Tentang Senam Lansia dengan Keaktifan Mengikuti Senam Lansia di Unit Rehabilitasi Sosial Wening Wardoyo Ungaran. Karya IIm S1 IImu Keperawatan. 2012;002.

7. Rahmi U, Somantri B, Yusrina N, Alifah N. Gambaran Pengetahuan Lansia Mengenai Senam Lansia. J Pendidik Keperawatan Indones. 2016;2(1):38-43.

8. Sari AN, Noviyasari E. Hubungan Pengetahuan lbu Premenopause Tentang Osteoporosis dengan Sikap Ibu Dalam Mencegah Terjadinya Osteoporosis (Di RW06 Kelurahan Bawang, Kecamatan Pesantren, Kota Kediri). 2016;5(2):76-81.

9. Janssen JAMJL. Impact of Physical Exercise on Endocrine Aging. Front Horm Res. 2016;47:68-81.

10. Karmila K, Kartika K, Arnita A. Faktor Yang Mempengaruhi Keikutsertaan Senam Lansia Di Wilayah Kerja Puskesmas Titue. An-Nadaa J Kesehat Masy. 2018;5(2):70.

11. Brunet J, Sabiston CM. Exploring motivation for physical activity across the adult lifespan. Psychol Sport Exerc [Internet]. 2011;12(2):99-105. Available from: http://dx.doi.org/10.1016/j.psychsport.2010.09.006

12. Bauman AE, Reis RS, Sallis JF, Wells JC, Loos RJF, Martin BW, et al. Correlates of physical activity: Why are some people physically active and others not? Lancet [Internet]. 2012;380(9838):258-71. Available from: http://dx.doi.org/10.1016/S01406736(12)60735-1

13. Suseno DM. Faktor-Faktor Yang Mempengaruhi Keaktifan Lansia Dalam Mengikuti Kegiatan Posyandu Lansia Di Desa Kauman Kecamatan Polanharjo Kabupaten Klaten. 2012; Available from: http://eprints.ums.ac.id/20530/28/2._NASKAH_PUBLIKASI.pdf

14. Kemenkes RI. Analisis Lansia di Indonesia. Pus data dan Inf Kementeri Kesehat RI [Internet]. 2017;1-2. Available from: www.depkes.go.id/download.php?file=download/.../infodatin lansia 2016.pdf\%0A

15. Kemenkes RI. Peraturan Menteri Kesehatan Republik Indonesia Nomor 8 Tahun 2015. Kementrian Kesehat Indones. 2017;1-140.

16. Arini LA. Kualitas Hidup Menopause yang Rutin Melakukan Latihan Fisik Orhiba: Studi Pengukuran Menggunakan Kuisioner WHOQOL-BREF. 2018;27-35.

17. Sari AN, Istighosah N. Hubungan Olahraga, Kopi dan Merokok dengan Kualitas Hidup Wanita Menopause yang Tinggal Di Wilayah Pedesaan. J Ners dan Kebidanan (Journal Ners Midwifery). 2019;6(3):326-32. 